\title{
Neonatal mortality in the case of Felege Hiwot referral hospital, Bahir Dar, Amhara Regional State, North West Ethiopia 2016: a one year retrospective chart review
}

Tilahun Tewabe*, Yenatfanta Mehariw, Eyerusalem Negatie and Bertukan Yibeltal

\begin{abstract}
Background: Ethiopia is among the countries with the highest neonatal mortality with the rate of 37 deaths per 1000 live births. In spite of many efforts by the government and other partners, non significant decline has been achieved over the last 15 years. Thus, identifying the prevalence and associated factors of neonatal mortality is very crucial for policy and program improvement. This study was designed to assess neonatal mortality rate in Felege Hiwot referral hospital, North West Ethiopia.

Methods: A hospital based chart review was done in Felege Hiwot referral hospital based on patient charts from July 2015 to June 2016. The data were collected using structured checklists. The collected data was coded, filtered and entered in to Microsoft Excel 2007 and transferred to STATA version 12.0 for analysis. Binary logistic regression analysis was used to identify factors associated with neonatal mortality. A p - value of $<0.05$ was considered as significant.

Results: The prevalence of neonatal mortality in Felege Hiwot referral hospital was 13.29\% (95\% Cl: 10.09-17.07). Early age of the newborn ( $<7$ days) $[A O R=0.39(0.16-0.97)]$, gestational age at delivery $[A O R=2.14(1.0-4.52)]$, late initiation of breastfeeding $[A O R=2.89(0.99-8.38)]$, non exclusive breastfeeding $[A O R=6.77(3.04-15.07)]$, inadequate ante natal visit $[A O R=5.02(1.02-24.70)]$ were the determinant factors for neonatal death.

Conclusions: This study revealed that neonatal mortality is still high in the study area. Early age of the newborn, late initiation of breastfeeding, exclusive breastfeeding and ante natal vist were the determinant factors for neonatal mortality in the study area. Therefore, giving attention for newborns who are small for age, timely initiation of breastfeeding, exclusive breastfeeding and increasing ante natal visit were recommended to reduce neonatal mortality.
\end{abstract}

Keywords: Neonatal mortality, Felege Hiwot referral hospital, Bahir Dar, Ethiopia

\footnotetext{
* Correspondence: bezatewabe01@gmail.com

College of Medicine and Health Sciences, Bahir Dar University, Bahir Dar,

Ethiopia
}

(c) The Author(s). 2018 Open Access This article is distributed under the terms of the Creative Commons Attribution 4.0 International License (http://creativecommons.org/licenses/by/4.0/), which permits unrestricted use, distribution, and reproduction in any medium, provided you give appropriate credit to the original author(s) and the source, provide a link to the Creative Commons license, and indicate if changes were made. The Creative Commons Public Domain Dedication waiver (http://creativecommons.org/publicdomain/zero/1.0/) applies to the data made available in this article, unless otherwise stated. 


\section{Background}

Globally, 6.6 million kids died before celebrating their fifth birthday per year. About 5 million deaths occurred within the first 28 days of life. This showed nearly $44 \%$ of under five mortalities and $60 \%$ of infant mortalities are covered by neonatal deaths. Above $98 \%$ of neonatal mortalities occurred in developing countries. Sub Saharan Africa takes the highest rate of newborn death, these are regions having least improvement in decreasing neonatal death rates [1].

In Ethiopia there is a high prevalence neonatal mortality. The trends of neonatal mortality in the country has slight decrease over past 20 years. Which were 46 in 1991-1995, 42 in 1996-200, 39 in 2001-2005 and 37 in 2006-2011 per 1000 live births. In spite of this, around $63 \%$ of infant mortalities in the country happened within the first 28 days of newborns life [2].

Most cases of neonatal deaths i.e., 99\% occurred in low and middle income countries. Around half of the cases occurred among home deliveries, making the global rate of neonatal mortality 30 per 1000 live births [3].

Reducing this huge number of neonatal death is a major challenge in Ethiopia since the targeted health interventions proposed to cover most fatal causes of neonate are usually vary from those required to tackle under five mortality [2].

Neonatal mortality rate has shown slow decline i.e. by $0.9 \%$ per year from 1995 to 2010 . This high prevalence of early neonatal death comprises $74 \%$ of neonatal deaths $[2,4]$. And a study done in Jimma showed that neonatal mortality rate was 35.5 per thousand live births [5] and 14.4\% in Addis Ababa [6].

This number is higher than former countries with high prevalence of neonatal deaths such as India and Indonesia. This obviously showed the condition of neonatal deaths is still towering and non progressing telling targeted interventions with all partners at various levels [7, 8].

Therefore, the study was intended to assess neonatal mortality in Felege Hiwot Referral Hospital from July 2015 to July 2016.

\section{Methods}

\section{Study design and setting}

Institution based retrospective chart review was conducted in Felege Hiwot referral hospital based on patient charts from July 2015 to June 2016.

The study was conducted in Felege Hiwot Referral Hospital, Bahir Dar, North West Ethiopia. It is located $563 \mathrm{Kms}$ far from Addis Ababa. Felege Hiwot referral hospital officially commenced its function in 1963 and currently it delivers health care services with medical, surgical, gynecological, orthopedic, intensive care units, paediatrics and ophthalmological wards with a total of 375 beds and 561 staffs. Annually, nearly 6300 neonates were seen with different health problems. The neonatal unit has 60 beds, 5 pediatricians and 20 nurses.

The sample size was calculated with single population proportion formula and by taking into consideration: prevalence $(\mathrm{P})$ of neonatal mortality 43.8\% [9], confidence level (CL) 95\%, margin of error (d) 5, 10\% non response rate and by using simple random sampling technique a total of 410 neonatal charts were selected for study.

\section{Measurement}

Data collection was done by using checklists which were prepared by using similar studies done on related topics $[4,5,9]$. Which consists: socio demographic information, risk factors of neonatal deaths and health service utilization characteristics. Eight data collectors and two supervisors were participated in the data collection. Before the actual data collection started, training was given for data collectors and supervisors for 1 day about proper data collection and recording.

\section{Data analysis}

The collected data from patient charts were coded, filtered and entered in to Microsoft excel 2007 and transferred to STATA Version 12.0 for analysis. To identify factors associated with neonatal mortality, first bivariate analysis was done to each independent variable with the dependent variable. Those variables which were associated with neonatal mortality in the bivariate logistic regression analysis with $p$-value $<0.05$ were included in the multivariate logistic regression analysis. The strength of association was determined using odds ratio and 95\% confidence level. Statistical significance was stated at $P$ value of $<0.05$.

\section{Results}

\section{Socio demographic data and risk factors of neonatal} mortality

Out of 410 selected patient charts 391 neonatal charts were studied. The rest were discarded due to incompleteness. From all 275 (70.3\%) were neonates less than 7 days and 209 (53.5\%) were males. Regarding to the birth weight, 297 (76\%) were between 2001 and $4000 \mathrm{~kg}$. Most (76.5\%) of the neonates were delivered between 37 and 42 weeks of gestation. Among all neonates, 241 (61.6\%) were initiated breast milk within 1 hour of birth. From total 251 (64.9\%) neonates were on exclusive breastfeeding. About threefourths of the mothers 384 (72.6) had four or more ante natal care during their pregnancy. Majority of (96.5\%) the mothers delivered in the health institution and $253(64.7 \%)$ delivered normally through the vagina. Sepsis (23.8\%), preterm (12.5\%), pneumonia (10\%) were the main recorded problems of the 
Table 1 Risk factors affecting neonatal mortality in Felege Hiwot referral Hospital, Bahir Dar, Amhara Regional State, North West Ethiopia 2016

\begin{tabular}{|c|c|c|c|}
\hline Variables & Response & Frequency & Percent \\
\hline \multirow[t]{2}{*}{ Age } & $<7$ days & 275 & 70.3 \\
\hline & 8-28 days & 116 & 29.7 \\
\hline \multirow[t]{2}{*}{ Sex } & Male & 209 & 53.5 \\
\hline & female & 182 & 46.5 \\
\hline \multirow[t]{4}{*}{ Weight at birth } & $<1500$ kg & 15 & 3.8 \\
\hline & $1501-2000 \mathrm{~kg}$ & 69 & 17.6 \\
\hline & 2001-3999 kg & 297 & 76.0 \\
\hline & $>4000 \mathrm{~kg}$ & 10 & 2.6 \\
\hline \multirow[t]{2}{*}{ Origin } & Rural & 151 & 38.6 \\
\hline & urban & 240 & 61.4 \\
\hline \multirow[t]{3}{*}{ Week of delivery } & 37-42 weeks & 299 & 76.5 \\
\hline & $<37$ weeks & 63 & 16.1 \\
\hline & $>42$ weeks & 29 & 7.4 \\
\hline \multirow{3}{*}{$\begin{array}{l}\text { Breast feeding initiation } \\
\text { time }\end{array}$} & Within 30 min & 90 & 23.0 \\
\hline & With in $1 \mathrm{~h}$ & 151 & 38.6 \\
\hline & After one hour & 150 & 38.4 \\
\hline \multirow[t]{2}{*}{ Exclusive breast feeding } & Yes & 254 & 64.9 \\
\hline & No & 137 & 35.1 \\
\hline \multirow[t]{2}{*}{ Immunization status } & Yes & 380 & 97.2 \\
\hline & No & 11 & 2.8 \\
\hline \multirow[t]{5}{*}{ Number of ANC } & One & 2 & 0.5 \\
\hline & Two & 17 & 4.3 \\
\hline & Three & 87 & 22.2 \\
\hline & Four & 238 & 60.8 \\
\hline & Above four & 46 & 11.8 \\
\hline \multirow[t]{2}{*}{ Place of delivery } & Health center & 377 & 96.4 \\
\hline & home & 14 & 4.6 \\
\hline \multirow[t]{3}{*}{ Mode of delivery } & Medical tool & 118 & 30.3 \\
\hline & Operation & 20 & 17.9 \\
\hline & Spontaneous & 253 & 64.7 \\
\hline \multirow[t]{2}{*}{ Congenital abnormality } & Yes & 3 & 0.8 \\
\hline & No & 388 & 99.2 \\
\hline \multirow[t]{2}{*}{ Chronic disease } & Yes & 15 & 3.8 \\
\hline & No & 376 & 96.2 \\
\hline \multirow[t]{8}{*}{ Problem after delivery } & Pneumonia & 39 & 10 \\
\hline & Sepsis & 93 & 23.8 \\
\hline & $\mathrm{CHF}$ & 9 & 3 \\
\hline & Jaundice & 18 & 3 \\
\hline & $\begin{array}{l}\text { Preterm/low birth } \\
\text { wt }\end{array}$ & 49 & 17 \\
\hline & Other (eg.DM, etc) & 183 & 18 \\
\hline & $\mathrm{CHD}$ & 9 & 2.3 \\
\hline & Jaundice & 18 & 4.6 \\
\hline
\end{tabular}

Table 1 Risk factors affecting neonatal mortality in Felege Hiwot referral Hospital, Bahir Dar, Amhara Regional State, North West Ethiopia 2016 (Continued)

\begin{tabular}{llll}
\hline Variables & Response & Frequency & Percent \\
\hline & Preterm/LBW & 49 & 12.5 \\
& Others & 183 & 46.8 \\
Chronic disease of mother & Yes & 23 & 5.9 \\
& No & 368 & 94.1 \\
\hline
\end{tabular}

neonate during admission and from all $13.29 \%$ of admitted neonates were died (Table 1 ).

\section{Factors associated with neonatal mortality}

The associations of the independent and dependent variables were first tested by using bivariate analysis. Variables which were associated $(p<0.05)$ in the bivariate analysis were tested in the final multivariate analysis to see their significant association with neonatal mortality. The identified independent predictor of neonatal mortality were: early age of the newborn, gestational age $<37$ weeks or preterm, late initiation of breastfeeding, non exclusive breastfeeding and inadequate ante natal visit.

Early age of the newborn (neonates in the first week) was significantly associated with neonatal mortality in the study area. Neonatal mortality was significantly higher at early age (first week) of the neonates than at later age $[\mathrm{AOR}=0.39(0.16-0.97)]$.

On the other hand gestational age at delivery was also significantly associated with the of neonatal mortality. The newborns who were preterm were two times higher to die than who were delivered term $[\mathrm{AOR}=2.14(1.0-4.52)]$.

Late initiation of breastfeeding was also associated with the occurrence of neonatal mortality. Mothers who initiate breastfeeding within 1 hour of birth of infant were almost three times higher to save their newborn than those who delayed breastfeeding initiation $[$ AOR $=2.89(0.99-8.38)]$.

Exclusive breastfeeding practice is known to save the life of a newborn. An infant who was not on exclusive breastfeeding was almost seven times higher to die than a neonate who was on exclusive breastfeeding $[\mathrm{AOR}=6.77$ (3.04-15.07)].

The number of ante natal vist was also associated with the prevalence of neonatal mortality. A neonate born from a mother with inadequate ante natal visit less than four times were almost five times higher to die than an infant born from a mother having adequate ante natal follow up [AOR $=5.02$ (1.02-24.70)] (Table 2).

\section{Discussion}

The prevalence of neonatal mortality in Felege Hiwot referral hospital was $13.29 \%$. This finding was higher than 
Table 2 Factors affecting neonatal mortality in Felege Hiwot referral Hospital, Bahir Dar, Amhara Regional State, North West Ethiopia 2016

\begin{tabular}{|c|c|c|c|c|c|c|}
\hline Variables & Response & Number of neonate & Number of deaths & Prevalence \% (95\% Cl) & Odds ratio $(95 \% \mathrm{Cl})$ & $P$-value \\
\hline \multirow[t]{2}{*}{$\overline{\text { Age }}$} & Early & 275 & 43 & 15.63(11.32-19.95) & $0.39(0.16-0.97)$ & 0.04 \\
\hline & Late & 116 & 9 & $7.76(2.85-12.66)$ & 1 & \\
\hline \multirow[t]{3}{*}{ Week of delivery } & 37- 38 weeks & 299 & 31 & 10.37(6.89-13.84) & 1 & - \\
\hline & $<37$ weeks & 63 & 21 & $33.33(21.56-45.10)$ & $2.14(1.0-4.52)$ & 0.04 \\
\hline & $>42$ weeks & 29 & 0 & - & - & - \\
\hline \multirow[t]{3}{*}{ Breast feeding initiation time } & Early & 90 & 5 & $5.56(0.78-10.33)$ & 1 & - \\
\hline & Timely & 151 & 14 & $9.27(4.62-13.93)$ & $1.23(0.39-3.90)$ & 0.73 \\
\hline & Lately & 150 & 33 & 22.0(15.33-28.67) & $2.89(0.99-8.38)$ & 0.04 \\
\hline \multirow[t]{2}{*}{ Exclusive breastfeeding } & Yes & 254 & 18 & 7.08(3.92-10.26) & $6.77(3.04-15.07)$ & 0.00 \\
\hline & No & 137 & 34 & 24.82(17.53-32.09) & 1 & \\
\hline \multirow[t]{5}{*}{ Number of ANC visit } & One & 2 & 0 & - & 1 & - \\
\hline & Two & 17 & 4 & 23.53(2.68-44.38) & $6.48(0,89-46.69)$ & 0.06 \\
\hline & Three & 87 & 14 & 15.91(8.19-23.62) & $2.35(0.45-12.26)$ & 0.31 \\
\hline & Four & 238 & 32 & 13.44(9.09-17.80) & $5.02(1.02-24.70)$ & 0.04 \\
\hline & More than four & 46 & 2 & $4.35(-1.6-10.32)$ & - & \\
\hline
\end{tabular}

$1=$ references, $p<.0 .05$ indicates significant variables

the prevalence reported in north Gonder [9] and Jimma zone Ethiopia [5]. The variations may be due to methodological differences among studies and dissimilarity in socio cultural, health service utilization and economical variations among study participants of the study areas.

Risk factors like chronic disease of the mother, problems after delivery, weight of the newborn and type of aid during delivery were the risk factors considered by other researchers $[4,9,10]$. However, in the current study: age of neonate less than 7 days, week of delivery, initiation of breast feeding, non exclusive breastfeeding and inadequate number of ANC visit were significantly associated with neonatal mortality.

Early age ( $<7$ days) of the newborn and being preterm were significantly associated with neonatal mortality. The occurrence of neonatal death was higher in preterm's than those born to term. Which consistent with studies $[8,10-16]$. This is due to the fact that being preterm exposes the new born for different conditions. Since they have many physiologic challenges to adapt extra uterine life. Due to this they are exposed to different fatal conditions like: hypothermia, respiratory center depression, different cardiovascular and hematological conditions like anemia, hyperbilirubinemia, immature immune defences which exposes them to infections, nutritional and gastrointestinal problems like poor feeding and entrocollitis, metabolic problems like hypoglycemia, fluid and electrolyte imbalance, low glomerular filtration rate and inability to handle water and solute loss are the major problems associated with preterm that increases the incidence of neonatal mortality.
Late initiation of breast feeding and non exclusive breastfeeding were the determinant factor for neonatal mortality. Neonatal mortality was higher in neonates who started breastfeeding after one hour and in those who were not on exclusive breastfeeding. Which is in line with studies done $[5,9]$. This due to breast milk is the ideal nutrient for the newborn, easily digestible absorbable and metabolized, promote bonding, improved behavioural and neurodevelopment, protects against various infectious diseases and promotes long term health which ultimately decreases neonatal mortality if it is practiced optimally.

Neonatal mortality was significantly associated with inadequate number of ante natal care visits. The danger of neonatal mortality was significantly reduced in those mothers who performed ANC visit four times and above than those who had less than four ANC visits. This is similar with the previous studies $[9,17,18]$. This may be due to proper ante natal vist increases early detection and management of the problems related with the pregnancy which ultimately improves the neonatal outcome.

Among the common diseases identified as a causes of neonatal mortality: pneumonia (5.13\%), sepsis (9.68), congestive heart failure (33.33), jaundice (16.67), premature delivery (34.69) and other unidentified causes (9. $84 \%)$. Which is consistent with studies $[9,11,14-16]$ where the most common conditions for neonatal mortalities were preterm, asphyxia, neonatal infections; diarrhoea, sepsis, pneumonia, tetanus, and congenital malformations. 


\section{Conclusions}

This study stated that the level of neonatal mortality is high in the study area. The great majority of neonatal deaths occurred in the first week of life, in neonates born preterm, not started breastfeeding on time, not on exclusive breastfeeding and in those mothers did not have adequate ante natal care visit. Recommendations to decrease neonatal mortality were: ensuring ante natal care during pregnancy, proper delivery care, and immediate postnatal care, increasing ante natal visits, delivering in health facility, providing comprehensive neonatal care, prevention and interventions of neonatal infection were recommended to reduce neonatal mortality.

\section{Limitations}

The study was identified based on the documented data and could not display all factors that are not documented in the patient's files, representativeness, completeness and quality of the recorded information.

\section{Abbreviations}

ANC: Anti natal care; DHS: Demographic and health survey; FHRH: Felege Hiwot Referral Hospital; ICU: Intensive care unit; MDG: Millennium development goal; NMR: Neonatal mortality rate; PROM: Premature rupture of membrane; SPSS: Statistical package soft ware; WHO: World Health Organization

\section{Acknowledgments}

We would like to thank Bahir Dar University, college of Medicine and Health Science School of nursing for the opportunity given to us to conduct this title. We would like to thank school of nursing for their support by writing letter of cooperation for Felege Hiwot Referral Hospital to get the data. We would like to thank the staff member of Felege Hiwot Referral Hospital for their cooperation to give available information about how to get neonatal mortality records.

\section{Availability of data and materials}

Anonymous of data has been included within the manuscript, however the raw data is kept confidential to protect patient identity.

\section{Authors' contributions}

All authors; TT, YM, EN, BY contributed for this study. Authors designed study, analyzed and interpreted data. $\Pi$ drafted the manuscript for considerable intellectual content. Authors reviewed the revised draft and approved the last version for submission.

\section{Ethics approval and consent to participate}

Ethical clearance was obtained from the college of medicine and health sciences institutional review board. Collected data were used for study purpose only; care and caution were exercised when data handled. A head of consulting secondary data sources, the neonatal department of Felege Hiwot Referral Hospital were requested for cooperation and offered permission for the study. The department were communicated about the purpose of the study.

\section{Competing interests}

The authors declare that they have no competing interests.

\section{Publisher's Note}

Springer Nature remains neutral with regard to jurisdictional claims in published maps and institutional affiliations.
Received: 12 February 2018 Accepted: 9 May 2018

Published online: 21 May 2018

\section{References}

1. Guevvera Y. World Health Organisation: Neonatal and perinatal mortality: country, regional and global estimates. 2006.

2. Central Statistics Agency (CSA) [Ethiopia], ORC Macro. Ethiopian demographic and health survey 2011. Addis Ababa,and Calverton: Central Statistical Authority and ORC Macro; 2011.

3. Lomazzi M, Borisch B, Laaser U. The millennium development goals: experiences, achievements and what's next. Glob Health Action. 2014;1; $7(1): 23695$.

4. Mekonnen Y, Tensou B, Telake DS, Degefie T, Bekele A. Neonatal mortality in Ethiopia: trends and determinants. BMC Public Health. 2013;13(1):483.

5. Debelew GT, Afework MF, Yalew AW. Determinants and causes of neonatal mortality in Jimma zone, Southwest Ethiopia: a multilevel analysis of prospective follow up study. PLoS One. 2014;9(9):e107184.

6. Girma T. Prevalence and associated factors of neonatal sepsis among neonates in Neonatal Intensive care Unit in selected Government Hospital Addis Ababa. AAU, Masters thesis; 2016.

7. Titaley CR, Dibley MJ, Agho K, Roberts CL, Hall J. Determinants of neonatal mortality in Indonesia. BMC Public Health. 2008;8(1):232.

8. Upadhyay RP, Dwivedi PR, Rai SK, Misra P, Kalaivani M, Krishnan A. Determinants of neonatal mortality in rural Haryana: a retrospective population based study. Indian Pediatr. 2012;49(4):291-4.

9. Kebede B, Gebeyehu A, Sharma HR, Yifru S. Prevalence and Associated factors of neonatal mortality in North Gonder Zone, North West Ethiopia. J Health Dev. 2012;26(2):66-71.

10. Kusuda S, Fujimura M, Sakuma I, Aotani H, Kabe K, Itani Y, Ichiba H, Matsunami K, Nishida H. Morbidity and mortality of infants with very low birth weight in Japan: center variation. Pediatrics. 2006;118(4):e1130-8.

11. Tariq P, Kundi Z. Determinants of neonatal mortality. J-Pakistan Med Assoc. 1999:49:56-9.

12. Lawn JE, Cousens S, Zupan J, Team LNSS. 4 million neonatal deaths: when? Where? Why? Lancet. 2005;365(9462):891-900.

13. Mahmood MA. Determinants of neonatal and post-neonatal mortality in Pakistan. The Pakistan Dev Rev. 2002:723-44.

14. Ansari N. The causes of neonatal mortality in Afghanistan. 2012.

15. Jehan I, Harris H, Salat S, Zeb A, Mobeen N, Pasha O, McClure EM, Moore J, Wright LL, Goldenberg RL. Neonatal mortality, risk factors and causes: a prospective population-based cohort study in urban Pakistan. Bull World Health Organ. 2009;87(2):130-8

16. Mah ME, Chiabi A, Tchokoteu PF, Nguefack S, Bogne JB, Siyou H, Soh FF, Mbonda E, Tchokoteu PF. Neonatal mortality in a referral hospital in Cameroon over a seven year period: trends, associated factors and causes. Afr Health Sci. 2014;14(3):517-25.

17. Bottoms SF, Paul RH, lams JD, Mercer BM, Thom EA, Roberts JM, Caritis SN, Moawad AH, Van Dorsten JP, Hauth JC, Thurnau GR. Obstetric determinants of neonatal survival: influence of willingness to perform cesarean delivery on survival of extremely low-birth-weight infants. Am J Obstet Gynecol. 1997;176(5):960-6.

18. Barros FC, Victora CG, Barros AJ, Santos IS, Albernaz E, Matijasevich A, Domingues MR, Sclowitz IK, Hallal PC, Silveira MF, Vaughan JP. The challenge of reducing neonatal mortality in middle-income countries: findings from three Brazilian birth cohorts in 1982, 1993, and 2004. Lancet. 2005;365(9462):847-54

\section{Ready to submit your research? Choose BMC and benefit from}

- fast, convenient online submission

- thorough peer review by experienced researchers in your field

- rapid publication on acceptance

- support for research data, including large and complex data types

- gold Open Access which fosters wider collaboration and increased citations

- maximum visibility for your research: over $100 \mathrm{M}$ website views per year

\section{At BMC, research is always in progress.}

Learn more biomedcentral.com/submissions 